\title{
Inhalt des 2. Bandes
}

4. Die Redaktion . . . . . . . . . . . . . . . 7

4.1 Ihr Aufbau .............. . 7

4.2 Die redaktionelle Arbeit im einzelnen . . . . . . . 11

4.3 Die Stoffbeschaffung . . . . . . . . . . . . . 18

4.3.1 Der eigenbeschaffte Stoff . . . . . . . . . . 19

4.3.2 Der fremdbeschaffte Stoff - Die Korrespondenzen 28

4.4 Die Stoffbearbeitung, die redaktionellen Sparten (Ressorts) . . . . . . . . . . . . . 36

4.4.1 Die Politik . . . . . . . . . . . 40

4.4.2 Der "Handelsteil“, der "volkswirtschaftliche Teil", die Sozialpolitik . . . ...... 53

4.4.3 Der Orts- und Heimatteil . . . . . . . . . . . 59

4.4.4 Der kulturelle Teil und seine publizistische Wertung. - Das Feuilleton - Der Feuilletonismus . .

4.4.4.1 Kultur und Zeitung-Der Begriff „Feuilleton“. . . . . . . . . . . . 70

4.4.4.2 Das Feuilleton als Sparte . . . . . . 74

4.4.4.2.1 Nachricht und Bericht. . . . . 75

4.4.4.2.2 Publizistische Wertung und Kritik 76

4.4.4.2.3 Unterhaltung und kulturelles

Beispiel . . . . . . . 90

4.4.4.3 Der Feuilletonismus - Stilform und journalistische Haltung . . . . . 107

4.4.5 Der Sportteil . . . . . . . . . . . . . . . 117

4.4.6 Die technische Redaktion - Natur und Wissenschaft ............. 120

4.4.7 Der Reiseteil . . . . . . . . . . . . 121

4.4.8 Das Lichtbild - Die Bildberichterstattung . . . 125

4.4.9 Umbruch und Aufmachung . . . . . . . . . . 132

4.5 Die Redaktion als organisiertes soziales System . . . 142

5. Die Technik und Wirtschaft im Zeitungsbetrieb . . . . 150

5.1 Das Hauptbuch des Verlages . . . . . . . . . . 151

5.2 Die Ausgaben . . . . . . . . . . . . . 154

5.2.1 Satz und Druck. . . . . . . . . . . 154

5.2.2 Papier . . . . . . . . . . . . 160

5.2 .3 Vertrieb . . . . . . . . . . . . . 162

5.2.4 Die Kosten der Redaktion . . . . . . . 169 
5.3 Die Einnahmen . . . . . . . . . . . 172

5.3.1 Verkauf . . . . . . . . . . 172

5.3.2 Anzeigen . . . . . . . . . . . . . . . 178

5.3.2.1 Die Anzeigenarten . . . . . . . 182

5.3.2.2 Zeitungsanzeigen als Werbemittel ... 184

5.3.2.3 Auflage und Anzeige. Die werbewirtschaftlichen Grundlagen . . . . . . 192

5.3.2.4 Textliche Fassung und graphische Form der Anzeige .......... 197

5.3.3 Einnahmen aus Nebenbetrieben - Zeitungsfremde Zuschüsse . . . . . . . . 2 200

5.4 Das Kostengesetz der Zeitung . . . . . . . . . . . 203

5.4.1 Das Verhältnis von Einnahmen und Ausgaben 203

5.4.2 Folgen: Kooperation und Konzentration in der deutschen Tagespresse ......... 212

5.5 Der Leser . . . . . . . . . . . . . . . . . . 231

6. Die Sicherung der öffentlichen Aufgabe . . . . . . . 247

Literatur . . . . . . . . . . . . . 260

Register ............... 269 